\title{
The Acquisition of Grammatical Gender in Arabic Demonstratives by English Native Speakers
}

\author{
Anwar Saad Aljadani \\ Correspondence: Anwar Saad Aljadani, Arts and Humanities, King Abdulaziz University, Jeddah, Kingdom of Saudi \\ Arabia.
}

Received: March 14, 2019

doi:10.11114/ijce.v2i1.4179
Accepted: March 25, 2019 Online Published: March 26, 2019

URL: https://doi.org/10.11114/ijce.v2i1.4179

\begin{abstract}
Recently, an increase interest in the acquisition of grammatical gender by second language (L2) learners has been revealed. This paper investigated the acquisition of Arabic, a language that has a rich grammatical gender system, by speakers of a first language (L1) that does not have gender (English). Arabic demonstrative pronouns selected as the linguistic feature to be investigated. Due to the gender differentiations, Arabic has nearly ten demonstrative pronouns whereas English has four demonstrative pronouns. Consequently, learnability considerations, the Full Transfer/Full Access (FT/FA) hypothesis presumes that English learners of Arabic will have the ability to acquire L2 grammatical gender despite the absence of these systems in their L1. However, the Failed Functional Features (FFF) hypothesis predicts that English learners of Arabic cannot acquire these systems since they are not available in their L1. This paper investigated the ability of English learners of Arabic in acquiring the Arabic demonstrative pronouns with their gender as accurate as native speakers of Arabic do. Moreover, does the proficiency level play a role in the acquisition of demonstratives? Finally, which hypothesis will be supported by the findings? It was found that L2 learners did not acquire the phenomenon as accurate as the native speakers did. Furthermore, proficiency level played a role in the acquisition of demonstratives as a significant disparity between L2 learners' levels was appeared. Finally, the current outcomes could be attributed to FT/FA hypothesis.
\end{abstract}

Keywords: demonstratives, the full transfer/full access hypothesis, the failed functional features hypothesis, the acquisition of grammatical gender, second language learners

\section{Introduction}

A series of empirical investigations have explored the adult acquisition of second language (L2). One frequent observation is that first language (L1) has an important influence in the acquisition of L2 by transferring L1 grammar into L2 grammar. Despite of this observation, adult L2 learners can access to Universal Grammar (UG) and can acquire what L1 learners do. This observation of accessing to UG has three logical possibilities. It can be understood first as full access where adult L2 learners fully access to UG (Schwartz \& Sprouse, 1994, 1996). The second understanding is the partial access where adult L2 learners can only partially access UG and cannot acquire grammatical features that are not present in their L1, suggesting fossilisation. Finally, adult L2 learners cannot access to UG and will not be able to reach native-like levels of ultimate attainment due to the absence of certain grammatical features in their L1 (Bley-Vroman, 1990). A phenomenon that may appear to be a persistent obstacle for L2 learners even in advanced level is the acquisition of grammatical gender. Grammatical gender is a system that divides all nouns into gender classifications. This system marks associated arguments (e.g. determiners, adjectives, demonstrative, relative pronouns) in the sentence for gender agreement (Comrie, 1999; Corbett, 1991). This system is found in several languages around the world. Moreover, some of these languages have a complex system such as Arabic and German. Conversely, some languages do not have a grammatical gender system such as English and Chinese. Grammatical gender in demonstrative pronouns is selected as the linguistic feature that will be utilised in the present endeavour to investigate the acquisition of L2 knowledge. The grammatical gender system might be considered as one of the most difficult structures that L2 learners have to acquire even at advance level (Dewaele \& Véronique, 2001; Bruhn de Garavito \& White, 2002; Scherag et al., 2004; Franceschina, 2005; Hulk \& Cornips, 2006). The current investigation explores the acquisition of pronouns gender agreement in Arabic by English native speakers. It will focus on the acquisition of demonstrative pronouns. Arabic has a rich grammatical gender system. It composes of two gender classes: masculine and feminine which can be applied to nouns, verbs, adjectives and pronouns. However, English does not have a grammatical gender system. 
The acquisition of grammatical gender is probably one of the most difficult syntactic features which L2 learners face even at advanced level (Scherag, et al., 2004; Franceschina, 2005). To date, the acquisition of Arabic grammatical gender as an L2 is a topic that has not received much attention and not been extensively investigated as it should be. Consequently, carrying out an investigation of the acquisition of Arabic grammatical gender by adult L2 learners is an attempt to provide an insight to avoid the challenges that Arabic L2 learners may encounter or at least provide a solution to overcome these obstacles and assist L2 learners to straightforwardly acquire such a linguistic phenomenon.

This paper begins by presenting a brief introduction of demonstrative pronouns in English and Arabic. It will then go on to highlight a shine on the role of L1 on the acquisition of L2, and the acquisition of grammatical gender followed by a summary of certain previous studies of the acquisition of grammatical gender. Next section describes the methodology of the experimental study. Section three lays out the results of the study, which are going to be discussed in section four. Finally, the conclusion will be presented.

\section{Demonstrative pronouns in English and Arabic}

English demonstratives are utilised as demonstrative pronouns or followed by nouns to indicate number and distance to the speaker. That is grammatical gender is not implied in English demonstrative pronouns. English has four demonstrative pronouns: this, that, these, and those. 'This' indicates a single referent near the speaker while 'that' is utilized to refer to a single referent far away from the speaker. 'These' is used to indicate plural referents near the speaker while 'those' indicates to point towards the distance plural referents from the speaker, illustrated in the following examples:

(1) a. This is a yellow school bus.

b. This school bus is yellow.

(2) a. That is a famous castle.

b. That castle is famous.

(3) a. These are intelligent people.

b. These people are intelligent

(4) a. Those are good students.

b. Those students are good.

Arabic demonstrative pronouns are used in the same way as English demonstrative pronouns; they are used as demonstrative pronouns or followed by nouns. However, Arabic has a wider range of demonstrative pronouns than English does due to the gender and number differentiations. It is vital to ensure the agreement between the demonstrative pronoun and the noun it refers to in gender, number and case. Arabic has nearly ten demonstrative pronouns which are classified into two classifications: demonstratives of proximity and demonstrative of distance. Demonstratives of proximity are haadhaa which refers to a masculine singular noun, haadhihi to refer to a feminine singular noun, haadhaani to refer to a masculine dual noun (in the nominative case), haataani to refer to a feminine dual noun (in the nominative case), haadhayni to refer to a masculine dual noun (in the accusative and genitive cases), haatayni to refer to a feminine dual noun (in the accusative and genitive cases) and haa 'ulaa' to refer to masculine and feminine plural nouns. haa'ulaa' has no gender differentiation and is utilised only when indicating human beings. The demonstrative pronoun referring to nonhuman plurals is the feminine singular demonstrative haadhihi. These demonstratives will be exemplified in the following examples:

$\begin{array}{ccl}\text { (5) a. haadhaa } & \text { manzil-un } & \text { qadiym-un } \\ \text { this } & \text { house-Nom } & \text { old-Nom } \\ \text { 'This is an old house.' } & \\ \text { b. haadhihi } & \text { fataat-un } & \text { jamiylat-un } \\ \text { this } & \text { girl-Nom } & \text { beautiful-Nom } \\ \text { 'This is a beautiful girl.' } & \\ \text { c. haadhaani } & \text { kitabani } & \text { mufiydani } \\ \text { these } & \text { two books } & \text { useful } \\ \text { 'These are two useful books.' } & \\ \text { d. haataani } & \text { qišataani } & \text { shayiqtaani } \\ \text { these } & \text { two stories } & \text { interesting }\end{array}$


'These are two interesting stories.'

$$
\begin{array}{cll}
\begin{array}{c}
\text { e. haa'ulaa' } \\
\text { these }
\end{array} & \text { tulaab-un } & \text { najihoon } \\
& \text { students (m)-Nom } & \text { successful }
\end{array}
$$

'These are successful students.'

$$
\begin{array}{cll}
\text { f. haa'ulaa' } & \text { talibaat-un } & \text { najihaat-un } \\
\text { these } & \text { students (f)-Nom } & \text { successful-Nom }
\end{array}
$$

'These are successful students.'

Demonstratives of distance are dhaalika which used to indicate a masculine singular noun, tilka is used to refer to feminine singular noun, dhaanika is used to refer to a masculine dual noun (in the nominative case), taanika is used to refer to indicate a feminine dual noun (in the nominative case), dhayni is used to refer to a masculine dual noun (in the accusative and genitive cases), taynika is used to indicate a feminine dual noun (in the accusative and genitive cases) and 'uulaa' $k a$ is used to indicate masculine and feminine plural nouns.

$$
\begin{array}{cll}
\text { (6) a. dhaalika } & \text { manzil-un } & \text { qadiym-un } \\
\text { that } & \text { house-Nom } & \text { old-Nom }
\end{array}
$$

'That is an old house.'

$$
\begin{array}{cll}
\text { b. tilka } & \text { fataat-un } & \text { jamiylat-un } \\
\text { that } & \text { girl-Nom } & \text { beautiful-Nom }
\end{array}
$$

'That is a beautiful girl.'

$$
\begin{array}{cl}
\text { c. dhaanika kitabani mufiydani } \\
\text { those }
\end{array}
$$

'Those are two useful books.'

$$
\begin{array}{cll}
\text { d. taanika } & \text { qišataani } & \text { shayiqtaani } \\
\text { those } & \text { two stories } & \text { interesting }
\end{array}
$$

'Those are two interesting stories.'

$$
\begin{aligned}
& \text { e. 'uulaa'ka tulaab-un najihoon } \\
& \text { those students (m)-Nom successful } \\
& \text { 'Those are successful students.' } \\
& \begin{array}{cll}
\text { f. 'uulaa'ka } & \text { talibaat-un } & \text { najihaat-un } \\
\text { those } & \text { students (f)-Nom } & \text { successful-Nom }
\end{array}
\end{aligned}
$$

'Those are successful students.'

\section{The role of $L 1$ in the acquisition of $L 2$}

The phenomenon of the vital role of L1 influence on the acquisition of L2 has been widely recognised by both practicing language teachers and L2 researchers for decades. Specifically, the role of the mother tongue in the L2 learning has been a major concern in applied linguistics inquiries for some time now. However, it is a widely believed by L2 acquisition researchers such as Schwartz \& Sprouse (1996) that the initial state of L2 acquisition is the L1 grammar. Moreover, other researchers such as Lefebvre, White \& Jourdan (2006) claim that the L1 influence will remain even to advanced L2 learners unless they are provided with positive evidence to enable them to develop their language. The role which L1 plays in the acquisition of L2 is very debatable. It can be stated that there are three logical possibilities for the degree of L1 transfer: no transfer, partial transfer or full transfer. In the case of no transfer, L1 has no influence on the acquisition of L2. Partial transfer is understood to mean that certain L1 properties are carried over into the L2 grammar at least in the initial state of L2 acquisition. Full transfer is defined as all L1 grammar is carried over into L2 grammar at least in the initial state of L2 acquisition. The no transfer possibility anticipates that no differences can be observed between L2 learners from a variety of L1 backgrounds. The partial transfer and full transfer anticipate that differences will be occurred between L2 learners from different L1 backgrounds at certain stage of the acquisition of L2.

\section{The acquisition of grammatical gender}

Grammatical gender is one of the earliest properties to be acquired in first language (L1) acquisition (Franceschina, 
2005). In the L1 acquisition, children use a variety of spate of gender indications which are available in their L1, namely syntactic, morphophonological and semantic indications. They go through two stages. Firstly, they rely on morphophonological indications more than syntactic and semantic indications. Late when they become older, they will start depending on the syntactic and semantic indications which means that they are aware of the meaning of the gendered nouns and the grammatical categories involved in the gender system of their L1, (e.g. articles, adjectives, and verbs) (Berman, 1986; Koehn, 1994; Franceschina, 2005).

On the other hand, several studies found that some L2 learners faced serious difficulties with the acquisition of grammatical gender (Bruhn de Garavito \& White, 2002; Carroll, 1989; Dewaele \& Véronique, 2001; Franceschina, 2005; Hulk \& Cornips, 2006a; Scherag, et al., 2004). The challenges associate with the acquisition of grammatical gender in L2 is a debatable phenomenon and many clarifications have been suggested to explain these difficulties. Various L2 researchers argued that the challenges which L2 learners face through the process of the acquisition of grammatical gender are due to L1 influence on acquisition of L2. Consequently, the absence of the grammatical gender feature in L1 as well as the variances in the grammatical gender system between L1 and L2 negatively impact the acquisition of grammatical gender in L2 acquisition (Carroll, 1989; Franceschina, 2005; Hawkins, 1998; Sabourin, 2001; Tsimpli \& Mastropavlou, 2007). It has been argued that L2 learners cannot acquire functional categorises or features after childhood unless such features are available in their L1 (Hawkins \& Chan, 1997; Franceschina, 2005; Hawkins \& Francescina, 2004). Nevertheless, some studies criticised this explanation and revealed that some L2 learners were able to acquire the grammatical gender despite the absence of such system in their L1 grammar (Bond et al., 2011; Bruhn de Garavito \& White, 2002; Ellis et al., 2004, 2012). However, some researchers referred the challenges to the learning strategies that used by L2 learners. Children use phonological and morphological indications to acquire grammatical gender at initial stages whereas L2 learners use semantic and syntactic indications to do so (Andersen, 1984; Cain et al., 1987; Finneman, 1992). Other researchers claimed that the difficulties in the acquisition of grammatical gender are contributed to an underspecification of the gender feature. L2 learners should complete their knowledge of the gender feature and know the right gender specification to avoid overgeneralization. The overgeneralization is a well-known phenomenon in language acquisition; children go beyond this stage and obtain their L1 whereas L2 learners may fossilize during this developmental stage (Hulk \& Cornips, 2006b; Brouwer et al., 2008).

This article further investigates the reality of L1 influence on the acquisition of L2. More specifically, it examines the Full Transfer/Full Access (FT/FA) hypothesis and the Failed Functional Features (FFF) hypothesis. These two hypotheses made contrast predictions on the possibility of accessing to L2 knowledge. The FT/FA hypothesis presumes that L2 learners have the ability to acquire L2 grammatical gender despite the presence or the absence of these systems in their L1. However, the FFF hypothesis predicts that L2 learners can only acquire what is available in their L1. That is, L2 learners whose L1s do not have gender systems or have different systems will not be able to acquire the L2 system. It focuses on the acquisition of Arabic demonstrative pronouns by English native speakers, in particular the current L2 learners' awareness of availability of gender classification in Arabic demonstrative pronouns.

\section{Previous investigations of the acquisition of grammatical gender}

A large number of studies have investigated the acquisition of grammatical gender in L2. Such a phenomenon has been explored under a variety of theoretical frameworks such as Universal Grammar (UG) (e.g. White et al, 2004; Franceschina, 2005) and error analysis (e.g. Rogers, 1987; Finneman, 1992). One example is that Sabourin (2001) explored the influence of L1 off-line processing by looking at how native speakers of German, Romance and English acquire Dutch grammatical gender. Dutch and German have a similar grammatical gender system. However, Romance has a grammatical gender system which is different from Dutch system. English has no grammatical gender system. The results showed that German and Romance participants performed quite similar to the control group while English participants performed significantly lower than the control group. L2 participants showed a hierarchical performance. The best performance was achieved by German participants followed by the Romance participants and the worse scores were performed by native speakers of English. It might be argued that L1 has a clear influence on the acquisition of L2 and the gender system should be available in L1 and similar to L2's system to be acquired.

Another study carried out by White et al. (2004) who examined the acquisition of Spanish gender and number agreement by English and French learners. French has a grammatical gender system whereas English does not have. The participants were classified into three proficiency levels: low, intermediate and advanced. The production and comprehension tasks were prepared to test the participants. The results showed that participants with lower proficiency were not only more accurate on number agreement than on gender agreement but also on masculine nouns more than feminine nouns. The advanced and intermediate participants performed about as accurately as native speakers did. These findings can be evidence of significant effects of proficiency and are in contrast with the influence of L1 and the prior exposure to an L2 with a gender system. They stated that their findings are consistent with the Full Transfer/Full Access hypothesis and do support the Failed Functional Features hypothesis. 
A further study was done by Ellis et al. (2012) who investigated the acquisition of grammatical gender in German by L2 learners whose L1s were either Afrikaans, English, or Italian. Italian has a gender system but it is not similar to that of German, whereas Afrikaans and English have no gender systems. It was found that Italian participants performed better than Afrikaans and English participants. Such findings can provide evidence of supporting the idea of L1 influence. The researchers further concluded that their results provide evidence for so-called "deep transfer" (transfer of abstract grammatical properties) from the L1 to the L2 in this area of L2 acquisition: since the grammatical gender systems of Italian and German are not congruent.

To date, the acquisition of English grammatical gender in L2 is a topic that has received much attention and been extensively explored with a variety of L1 backgrounds, including French, Turkish, Spanish, Arabic, Japanese, Korean, Russian and Chinese (for instance, Oliphant 1997; Meltem, 2015) However, the acquisition of Arabic grammatical gender by L2 learners may not be investigated as extensively as it should be. Certain experimental studies investigated the acquisition of Arabic grammatical gender by exploring not only the order in which L2 learners acquire some grammatical gender features but also the influence of the L1 on the acquisition of the $\mathrm{L} 2$ grammatical gender.

Bolotin (1996a) carried out an investigation to explore the ability of L2 Arabic learners to access UG. The study aimed to examine the extent to which L2 Arabic learners are able to reset the parameters of the Arabic relative clause. Participants were twenty-four native speakers of English, two native speakers of German and one native speaker of Polish. These participants were classified into three groups according to their proficiency level: ten were at beginner, eleven were at intermediate and six were at advanced. Six native speakers acted as a control group. The utilised grammaticality judgment task included simple and complex sentences that were grammatically correct in Arabic but not in English, and vice versa. It was found that there was a significant difference between the beginning and intermediate groups and the native speakers group. However, advanced group performed similarly to the control group. Bolotin stated that L1 has a vital role at the initial stages of L2 acquisition and L2 Arabic learners will have ultimately reset Arabic parameters.

Furthermore, Alhawary (2005) explored the acquisition of Arabic morphosyntactic structures including subject-verb agreement, noun-adjective agreement, and noun-adjective word order by L2 learners of a variety of L1 backgrounds to investigate the influence of the L1 on the acquisition of the $\mathrm{L} 2$ grammatical gender agreement based on three hypotheses within the context of UG and L1 influence: the Missing Surface Inflection (Lardiere, 2000), the Local Impairment (Beck, 1998), the FFF hypothesis (Hawkins \& Chan, 1997). Twenty- seven native English speakers and Twenty- six native French speakers were participated in this study. The participants were classified into three groups based on exposure to Arabic: first year, second year, and third year. French have a grammatical gender system whereas English does not have. The questionnaire included three picture tasks: picture description, picture differences, and picture sequencing. It was found that there was no significant difference between the L1 French groups and the L1 English groups with subject-verb agreement. Nevertheless, there was a significant difference between them with noun-adjective agreement. It was not only revealed that English learners of Arabic faced more difficulty with formal gender than natural gender but also French learners outperformed English learners. However, some advanced English learners of Arabic obtained a perfect score. It was concluded that these findings did not support either the Local Impairment Hypothesis (Beck, 1998) or the FFFH (Hawkins \& Chan, 1997), but they were partially in the agreement with the Missing Surface Inflection Hypothesis. Moreover, Alhawary (2005) argued that these results are consistent with the FT/FA hypothesis.

Later, Alhawary (2009) investigated the acquisition of nominal gender agreement and verbal gender agreement based on longitudinal and cross-sectional studies. In the longitudinal research, eight English native speakers and one French native speaker were under observation for the length of a school year. The cross-sectional study included eighty- two L2 adult learners of Arabic of different L1 backgrounds: English, French, and Japanese. Both studies revealed that participants preferred using masculine gender more than feminine gender in the case of nominal gender agreement. Additionally, French learners performed significantly better than English and Japanese learners when adding the correct feminine gender marker to adjectives in order to agree with the corresponding feminine nouns. Both studies also showed that English and Japanese speakers seemed to face more challenge with nominal agreement than verbal agreement, as their performance on verbal agreement was relatively comparable to that of French learners. Moreover, no significant difference between all three groups with respect to verbal agreement was found. It was concluded that these results accord with the FT/FA hypothesis.

In the same vein, Al-Amry (2014) examined the acquisition of subject-verb gender agreement in Arabic by adult L2 learners with different L1 backgrounds at two different levels of proficiency by adopting the FT/FA and the FFF hypotheses. The participants were divided into two classifications based on the presence and the absence of grammatical gender system in their L1. The first class composed learners who have a grammatical gender system in their L1 and the second class composed learners who do not have a grammatical gender system in their L1. One comprehension and three production tasks were utilised to elicit the data. It was showed that the performance of L2 learners was not comparable to the native control group. Most importantly, no significant difference between the 
learners who have a grammatical gender system in their L1 and learners who do not have was statistically revealed, suggesting no influence of L1. However, the proficiency level has a significant effect as the advanced learners notably performed better than the intermediate learners. He stated that, to some extent, the results provided support to the Full Transfer/Full Access Hypothesis.

To the best of my knowledge, a few studies have investigated the acquisition of grammatical gender agreement in Arabic by L2 learners, specifically in relation to the UG and transfer hypotheses. Therefore, the present study is undertaken to attempt to provide a contribution to $\mathrm{L} 2$ acquisition researches by providing evidence in this domain by examining the acquisition of Arabic demonstrative pronouns by English native speakers.

\section{Research questions}

The current study intends to investigate these areas of disparities between the FT/FA and the FFF hypotheses by exploring the acquisition of the grammatical gender system in Arabic by English native speakers. It seeks to investigate the ability of English learners in acquiring the Arabic demonstrative pronouns with their gender as accurate as native speakers of Arabic do. It also explores the extent of which the proficiency level plays a role in the acquisition of Arabic demonstrative pronouns. Finally, which hypothesis will be supported by the present study?

\section{Methodology}

\section{Participants}

Two major groups will contribute to this study: one group will be the experimental group that made up of fifty English speakers learning Arabic as L2 and this group will be subdivided into two groups based on the participants' proficiency level: pre-intermediate and upper-intermediate. The second group consisted of ten native speakers of Arabic who acted as controls to certify the reliability and validity of the used test.

\section{Materials}

\section{Grammaticality Judgment Task (GJT)}

The participants were given written grammaticality judgment task which involved two variations of items: the investigated items and the distractor items. Both items and their assortments of different structures were randomly ordered to avoid possible ordering influences. The investigated items consisted of thirty-two sentences describing eight demonstrative pronouns haadhaa, haadhihi, haadhaani, haataani, dhaalika, tilka, dhaanika and taanika. Each pronoun will be described in four sentences: two grammatical and two ungrammatical to preserve their awareness in the assessing of the grammatical and ungrammatical sentences. Each sentence was followed by a five-point Likert scale from -2 (completely impossible in Arabic) through 0 (unable to decide) to 2 (completely possible in Arabic).

\section{Results}

Table 1. Comparison between the participants assessing the grammatical gender sentences

\begin{tabular}{|c|c|c|c|c|c|}
\hline Groups of participant & $\mathrm{N}$ & Means & $\mathrm{t}$ & Df & Sig. \\
\hline Arabic native speakers & 10 & 1.82 & 387 & 3278 & $00 \Omega$ \\
\hline Pre-intermediate learners of Arabic & 25 & 1.04 & 3.87 & 32.78 & .000 \\
\hline Arabic native speakers & 10 & 1.82 & 1.30 & 27.50 & .204 \\
\hline Upper-intermediate learners of Arabic & 25 & 1.69 & 1.30 & 21.50 & .204 \\
\hline $\begin{array}{l}\text { Pre-intermediate learners of Arabic } \\
\text { Unper-intermediate learners of Arabic }\end{array}$ & $\begin{array}{l}25 \\
25\end{array}$ & $\begin{array}{l}1.04 \\
1.69\end{array}$ & 4.53 & 48 & .000 \\
\hline
\end{tabular}

Table 1 provides a statistical analysis of the judgment of the grammatical gender sentences. The independent samples t-test was run between participant groups (native speakers of English, upper-intermediate learners and pre-intermediate learners of English) on their assessment of the grammatical sentences. The statistical analysis showed a significant disparity not only between native speakers of Arabic and the pre-intermediate learners of Arabic $(t=3.87, d f=32.78, p$ $=.000)$, but also between the $\mathrm{L} 2$ learners' groups $(\mathrm{t}=4.53, \mathrm{df}=48, \mathrm{p}=.000)$. Interestingly, no remarkable variance was observed between native speakers group and the upper-intermediate group $(\mathrm{t}=1.30, \mathrm{df}=27.50, \mathrm{p}=.204)$.

Table 2. Comparison between the participants assessing the ungrammatical gender sentences

\begin{tabular}{|c|c|c|c|c|c|}
\hline Groups of participant & $\mathrm{N}$ & Means & $\mathrm{t}$ & Df & Sig. \\
\hline Arabic native speakers & 10 & -1.68 & 60 & 2001 & 000 \\
\hline Pre-intermediate learners of Arabic & 25 & -.59 & -0.0 & 20.01 & .000 \\
\hline Arabic native speakers & 10 & -1.68 & -1.69 & 14.21 & .111 \\
\hline Upper-intermediate learners of Arabic & 25 & -1.41 & -1.09 & 14.21 & .111 \\
\hline $\begin{array}{l}\text { Pre-intermediate learners of Arabic } \\
\text { Upper-intermediate learners of Arabic }\end{array}$ & $\begin{array}{l}25 \\
25\end{array}$ & $\begin{array}{c}-.59 \\
-1.41\end{array}$ & -6.1 & 42.49 & .000 \\
\hline
\end{tabular}

Table 2 presents an overview of a statistical analysis of the judgment of the ungrammatical gender sentences. The 
results, as revealed in the table, indicate that a significant difference between the native speakers and the pre-intermediate learners can be observed $(t=-6.0, \mathrm{df}=20.01, \mathrm{p}=.000)$. Moreover, the pre-intermediate learners differed significantly from the upper-intermediate learners $(\mathrm{t}=-6.1 \mathrm{df}=42.49, \mathrm{p}=.000)$. However, no significant difference between the native speakers and the upper-intermediate learners was evident $(\mathrm{t}=-1.69, \mathrm{df}=14.21, \mathrm{p}=.111)$.

\section{Discussion}

The results of the current study showed a divergent finding based on the proficiency level of L2 learners. The significant disparity between the pre-intermediate learners and the native speakers did not reveal between the same native speakers and the upper-intermediate learners. In spite of the richness and complication of grammatical gender in Arabic demonstrative pronouns, the results did not reveal a problematic for upper-intermediate English learners of Arabic. However, the pre-intermediate learners faced difficulties to acquire the grammatical gender in Arabic demonstrative pronouns.

An initial objective of the current paper was to investigate the ability of English learners of Arabic in acquiring the grammatical gender in demonstrative pronouns as English lacks the grammatical gender system. It was found that English learners did not perform as accurate as native speakers of Arabic did. However, a learner at the pre-intermediate level and three learners at the upper-intermediate level performed as readily as the native speakers performed. Despite the inaccurate performance, there was an obvious absence of the significant disparity between the upper-intermediate learners and the native speakers which may be understood as they did not face any difficulties in mastering the grammatical gender in the Arabic demonstrative pronouns comparing to the pre-intermediate learners. Moreover, all the participants in the current study dealt more accurately with the accepting the grammatical sentences than the rejecting of the ungrammatical sentences. This observation may be evident that positive evidence is effectively available to the learners more than negative evidence.

Secondly, it sought to determine the effect of the proficiency levels in the acquisition of Arabic demonstrative pronouns. It was showed that the proficiency levels had a significant influence on the acquisition of demonstrative pronouns in Arabic by native speakers of English due to the significant disparity between their groups, as shown in Table 1 and 2. The appearance of the significant disparity between the two proficiency levels could be understood as the upper-intermediate learners seem to acquire grammatical gender more successfully than the pre-intermediate learners although both groups did not reach native- like performance.

The final purpose is to determine which hypothesis the FT/FA or the FFF will be supported by the current outcomes. The outcomes of the current study revealed that the English learners of Arabic did not rate the sentences as readily as the native speakers rated even though there is an absence of the significant difference between the upper-intermediate learners and the native speakers. Moreover, the upper-intermediate learners performed more accurate than the pre-intermediate learners. The inaccuracy of L2 learners' performance compared to the native speakers' performance does not appear to be evident of either the FT/FA or the FFF hypotheses. However, the performance of some L2 learners was as accurate as the native speakers' performance. Such observation is not only in agreement with the FT/FA hypothesis but also can be a supportive evidence to those of previous studies (White et al, 2004; Alhawary, 2005, 2009; Bond et al., 2011) who were in the with the FT/FA hypothesis.

\section{Conclusion}

Grammatical gender is a system that divides all nouns into gender classifications. This system marks associated arguments (e.g. determiners, adjectives, demonstrative, relative pronouns) in the sentence for gender agreement. The acquisition of grammatical gender is probably one of the most difficult syntactic features which L2 learners face even at advanced level (Scherag, et al., 2004; Franceschina, 2005). Unsurprisingly, the grammatical gender system is variously found in several languages around the world. Some of these languages have a complex system such as Arabic and German while some languages do not have a grammatical gender system such as English and Chinese. Arabic demonstrative pronouns and their acquisition by English learners are taken as an illustration of the complexity of Arabic grammatical gender. Arabic has a wider range of demonstrative pronouns than English does due to the gender differentiations. Arabic has nearly ten demonstrative pronouns. English, however, has four demonstrative pronouns. The current investigation aimed to examine the ability of English native speakers in acquisition of Arabic demonstrative pronouns with their gender as accurate as native speakers of Arabic do. It also explored the extent of which the proficiency level plays a role in the acquisition of Arabic demonstrative pronouns. Finally, which hypothesis will be supported by the present study? It was found that the upper-intermediate learners did not vary significantly from the native speakers whereas the pre-intermediate learners varied. It also showed that the proficiency level played a role in the acquisition of Arabic demonstrative pronouns as the upper-intermediate learners performed more accurate than the pre-intermediate learners. The current finding could be in some way evident to the FT/FA hypothesis. 


\section{Acknowledgement}

I am grateful to my colleagues Dr. Saeed Alahmari and Dr. Yasser Alsulami for their valuable discussion and beneficial suggestions. Gratefulness is also extended to Deanship of Scientific Research at King Abdulaziz University for their financial support.

\section{References}

Al-Amry, A. (2014). The acquisition of gender agreement in adult learners of Arabic. MA. diss., Ottawa: Carleton University.

Alhawary, M. (2005). L2 acquisition of Arabic morphosyntactic features: Temporary or permanent impairment? In Alhawary, M. \& Benmamoun, E. (Eds.), Perspectives on Arabic linguistics (p. 273-312). Amsterdam: John Benjamins. https://doi.org/10.1075/cilt.267.14alh

Alhawary, M. (2009). Arabic second language acquisition of morphosyntax. Yale University Press.

Andersen, R. (1984). What's gender good for anyway? In Andersen, R. (Ed.), Second language: A cross-linguistic perspective (p. 77-100). Rowley, MA: Newbury House.

Beck, M. L. (1998). L2 acquisition and obligatory head movement: English-speaking learners of German and the Local impairment hypothesis. In: Studies in Second Language Acquisition, 20(3), 311-348. https://doi.org/10.1017/S0272263198003027

Berman, R. (1986). Acquisition of Hebrew. In Slobin, D. I. (Ed.), The crosslinguistics study of language acquisition (p. 255-372). Hillsdale, NJ: Lawrence Erlbaum.

Bley-Vroman, R. (1990). The logical problem of foreign language learning. Linguistic Analysis, 20, 3-49.

Bolotin, N. (1996a). Resetting Parameters in Acquiring Arabic. In M. Eid and D. Parkinson (Eds.), Perspectives on Arabic Linguistics, (pp. 166-178). Amsterdam. The Metherlands: John Benjamins. https://doi.org/10.1075/cilt.141.13bol

Bond, K., Gabriele, A., Fiorentino, R., \& Banon, J. (2011). Individual differences and the role of the L1 in L2 processing: An ERP investigation. In Herschensohn, J. D. (Eds.), Tanner proceedings of the 11th generative approach to second language acquisition conference GASLA (p. 17-29). Somerville, MA: Cascadilla Proceedings Project.

Brouwer, S., Cornips, L., \& Hulk, A. (2008). Misrepresentation of Dutch neuter gender in older bilingual children. In Haznedar, B. \& Gavruseva, E. (Eds.), Current trends in child second language acquisition: A generative perspective (p. 83-96). Amsterdam: John Benjamins. https://doi.org/10.1075/lald.46.06bro

Bruhn De Garavito, J., \& White, L. (2002). The second language acquisition of Spanish DPs: The status of grammatical features. In Pérez-Leroux, A. \& Munoz Liveras, J. (Eds.), The acquisition of Spanish morphosyntax (p. 153-178). Dordrecht: Kluwer. https://doi.org/10.1007/978-94-010-0291-2_6

Cain, J., Weber-Olsen, M., \& Smith, R. (1987). Acquisition strategies in a first and second language: Are they the same? Journal of Child Language, 14(2), 333-352. https://doi.org/10.1017/S0305000900012964

Carroll, S. E. (1989). Second language acquisition and the computational paradigm. Language Learning, 39(4), 535-594. https://doi.org/10.1111/j.1467-1770.1989.tb00902.x

Comrie, B. (1999). Grammatical gender systems: A linguist's assessment. Journal of Psycholinguistics Research, 28(5), 457-466. https://doi.org/10.1023/A:1023212225540

Corbett, G. G. (1991). Gender. Cambridge: Cambridge University Press. https://doi.org/10.1017/CBO9781139166119

Dewaele, J., \& Véronique, D. (2001). Gender assignment and gender agreement in advanced French interlanguage: A cross-sectional study. Bilingualism: Language and Cognision, 4(3), 275-297. https://doi.org/10.1017/S136672890100044X

Ellis, C., Conardie, S., \& Huddlestone, K. (2012). The acquisition of grammatical gender in L2 German by learners with Afrikaans, English or Italian as their L1. Stellenbosch Papers in Linguistics, 41, 17-27. https://doi.org/10.5774/41-0-131

Finneman, M. (1992). Learning agreement in the noun phrase: The strategies of three first-year Spanish students. IRAL, 30, 121-136. https://doi.org/10.1515/iral.1992.30.2.121

Franceschina, F. (2005). Fossilized second language grammars. Amsterdam: John Benjamins. https://doi.org/10.1075/lald.38 
Hawkins, R. (1998). Explaining the difficulty of French gender attribution for speakers of English. Paper presented at the 8th annual EUROSLA conference, Paris.

Hawkins, R., \& Chan, C. Y. H. (1997). The partial availability of Universal Grammar in second language acquisition: The "failed functional features hypothesis." Second Language Research, 13, 187-226. https://doi.org/10.1191/026765897671476153

Hawkins, R., \&. Franceschina, F. (2004). Explaining the acquisition of and non-acquisition of determiner-noun gender concord in French and Spanish. In P. Prévost and J. Paradis (eds.). The acquisition of French in different contexts: focus on functional categories. Amsterdam: John Benjamins. pp. 175-205. https://doi.org/10.1075/lald.32.10haw

Hulk, A., \& Cornips, L. (2006b). Neuter gender and interface vulnerability in child L2/2L1 Dutch. In Unsworth, S., Parody, T., Sorace, A. \& Young-Scholten, M. (Eds.), Paths of development in L1 and L2 acquisition: In honor of Bonnie D. Schwartz (p. 107-134). Amsterdam: John Benjamins. https://doi.org/10.1075/lald.39.06hul

Koehn, C. (1994). The acquisition of gender and Number morphology within NP. In Meisel, J. (Ed.), Bilingual first language acquisition: French and German grammar development (p. 29-51). Amsterdam: John Benjamins. https://doi.org/10.1075/lald.7.04koe

Lardiere, D. (2000). Mapping features to forms in second language acquisition. In Archibald, J., editor, Second language acquisition and linguistic theory. Oxford: Blackwell, 102-29.

Lefebvre, C., White, L., \& Jourdan, C. (2006). L2 acquisition and Creole genesis: dialogues, John Benjamins Publishing. https://doi.org/10.1075/lald.42

Oliphant, K. (1998). Acquisition of grammatical gender in Italian as a foreign language. The Canadian Modern Language Review/La Revue Canadienne Des Langues Vivantes, 54(2), 239-262. https://doi.org/10.3138/cmlr.54.2.239

Roger, M. (1987). Learners' difficulties with grammatical gender in German as a foreign language. Applied Linguistics, 8, 48-74. https://doi.org/10.1093/applin/8.1.48

Sabourin, L. (2001). L1 effects on the processing of grammatical gender in L2. Eurosla yearbook, 1(1), 159-169. https://doi.org/10.1075/eurosla.1.13sab

Scherag, A., Demuth, L., Roesler, F., Neville, H. J., \& Roeder, B. (2004). The effects of late acquisition of L2 and the consequences of immigration on L1 for semantic and morpho syntactic language aspects. Cognition, 93, B97-B108. https://doi.org/10.1016/j.cognition.2004.02.003

Schwartz, B. D., \& Sprouse, R. (1994). Word order and nominative case in nonnative language acquisition: a longitudinal study of (L1 Turkish) German interlanguage. Language acquisition studies in generative grammar, 31, 71-89.

Schwartz, B. D., \& Sprouse, R. A. (1996). L2 cognitive states and the full transfer/full access model. Second language research, 12, 40-72. https://doi.org/10.1177/026765839601200103

Tsimpli, I., \& Mastropavlou, M. (2007). Feature interpretability in L2 acquisition and SLI: Greek clitics and determiners. In Liceras, J., Zobl, H. \& Goodluck, H. (Eds.), The role of formal features in second language acquisition. Mahwah, NJ: Lawrence Erlbaum.

White, L., Valenzuela, E., Kozlowska-Macgregor, M., \& Leung, I. (2004). Gender and number agreement in non-native Spanish. Applied Psycholinguistics, 25, 105-133. https://doi.org/10.1017/S0142716404001067

\section{Copyrights}

Copyright for this article is retained by the author(s), with first publication rights granted to the journal.

This is an open-access article distributed under the terms and conditions of the Creative Commons Attribution license which permits unrestricted use, distribution, and reproduction in any medium, provided the original work is properly cited. 